\title{
Awareness, Cost-effectiveness, and Extension of Prosthodontic Treatment to Underprivileged Patients across Dental Colleges in India: A Cross-sectional Survey
}

\author{
${ }^{1}$ Smriti Ramdas, ${ }^{2}$ Rakshith C Guru, ${ }^{3}$ Sanjeela R Guru, ${ }^{4}$ R Sushma
}

\begin{abstract}
India being a developing nation has a significant percentage of population who are living in low socioeconomic conditions. Hence, health care is not considered a priority, and dental awareness is very low. Thus, spreading dental awareness among the poor, and motivating and counseling them will enable promotion of prosthodontic services in order to improve the oral health of patients with missing teeth. A questionnaire-based survey was formulated to evaluate dental colleges across India regarding their methods to spread awareness of dental treatment and various methods to extend the same to underprivileged people in the society. Results of the survey showed that though majority of the colleges were spreading awareness of dental treatment, very few of those were targeted at patients with low socioeconomic status.
\end{abstract}

Keywords: Awareness, Cost-effectiveness, Dental treatment, Prosthodontics.

How to cite this article: Ramdas S, Guru RC, Guru SR, Sushma R. Awareness, Cost-effectiveness, and Extension of Prosthodontic Treatment to Underprivileged Patients across Dental Colleges in India: A Cross-sectional Survey. J Health Sci Res 2018;9(1):1-5.

Source of support: Nil

Conflict of interest: None

\section{INTRODUCTION}

Loss of some or all teeth results in disruption of function as well as esthetics of an individual. This compromised oral status leads to inadequate dietary intake affecting nutritional status and also general health of the individual. Hence, replacement of missing teeth is important for restoring function and esthetics and for preserving the remaining oral structures. In a developing nation like India with poor literacy rate and most people having low socioeconomic conditions, motivation for dental

\footnotetext{
${ }^{1}$ Undergraduate Student, ${ }^{2}$ Professor, ${ }^{3,4}$ Reader

${ }^{1,2,4}$ Department of Prosthodontics, School of Dental Sciences Krishna Institute of Medical Sciences, Karad, Maharashtra, India

${ }^{3}$ Department of Periodontics, Vydehi Institute of Dental Sciences and Research Centre, Bengaluru, Karnataka, India

Corresponding Author: Rakshith C Guru, Professor, Department of Prosthodontics, School of Dental Sciences, Krishna Institute of Medical Sciences, Karad, Maharashtra, India, Phone: +919900197517, e-mail: rakshith77@yahoo.com
}

treatment is important. Available literature has shown that $70 \%$ of India's population is residing in the rural areas, while $80 \%$ of dentists are practicing in major cities. ${ }^{1}$

Patients have various reasons for not replacing their missing teeth, such as financial issues, lack of education, lack of time, and lack of awareness, etc. ${ }^{2}$ Underprivileged patients are generally of the opinion that dental treatment is expensive. Therefore, spreading awareness and counseling them will enable promotion of prosthodontic services in order to improve the oral health condition of patients with missing teeth. ${ }^{3-5}$ As majority of India's population live in rural areas, it is of paramount importance to look after their oral health for a better future.

Dental colleges can fulfill this unmet need through their outreach programs. Azad et $\mathrm{al}^{6}$ highlighted the significant role that dentists play in the spread of awareness about prosthodontic treatment and that they can also facilitate further spread of information to patient's friends and relatives.

The objective of the present survey was to assess the methods used by dental colleges across India to spread awareness of dental treatments, cost-effectiveness of the treatments provided, and also to assess use of new approaches to extend their treatment to underprivileged people. The questionnaire was also used to evaluate new approaches regarding extension of these treatments to underprivileged people.

\section{MATERIALS AND METHODS}

A cross-sectional survey was conducted using a selfstructured questionnaire which consisted of 15 questions of closed-ended, open-ended, and multiple-choice questions. The survey was undertaken after the due approval of the institutional ethical board following which a list of dental colleges on the Dental Council of India (DCI) website was obtained. A questionnaire was pilot-tested among four dental colleges to check the feasibility of the survey. The face validity of the questionnaire was checked by submitting it to five experts in the field of prosthodontics, who approved of the questionnaire before it was mailed to the dental colleges across India. Reliability of the questionnaire was checked by using Cronbach's alpha and it was found to be 0.08 . 
The questionnaire consisted of the following components:

- Methods of spreading awareness of dental treatment

- Cost-effectiveness of dental treatment provided

- Extension of prosthodontic treatment to underprivileged patients

The questionnaire was sent by e-mail to the principals of the 289 dental colleges listed on the DCI website. The mail questionnaire was accompanied by a letter which elaborated the objectives of the survey and also emphasized the importance of an immediate response. Figure 1 illustrates a sample of the survey questionnaire mailed to all participants. A time period of 2 months was given for the return of the answered questionnaires.

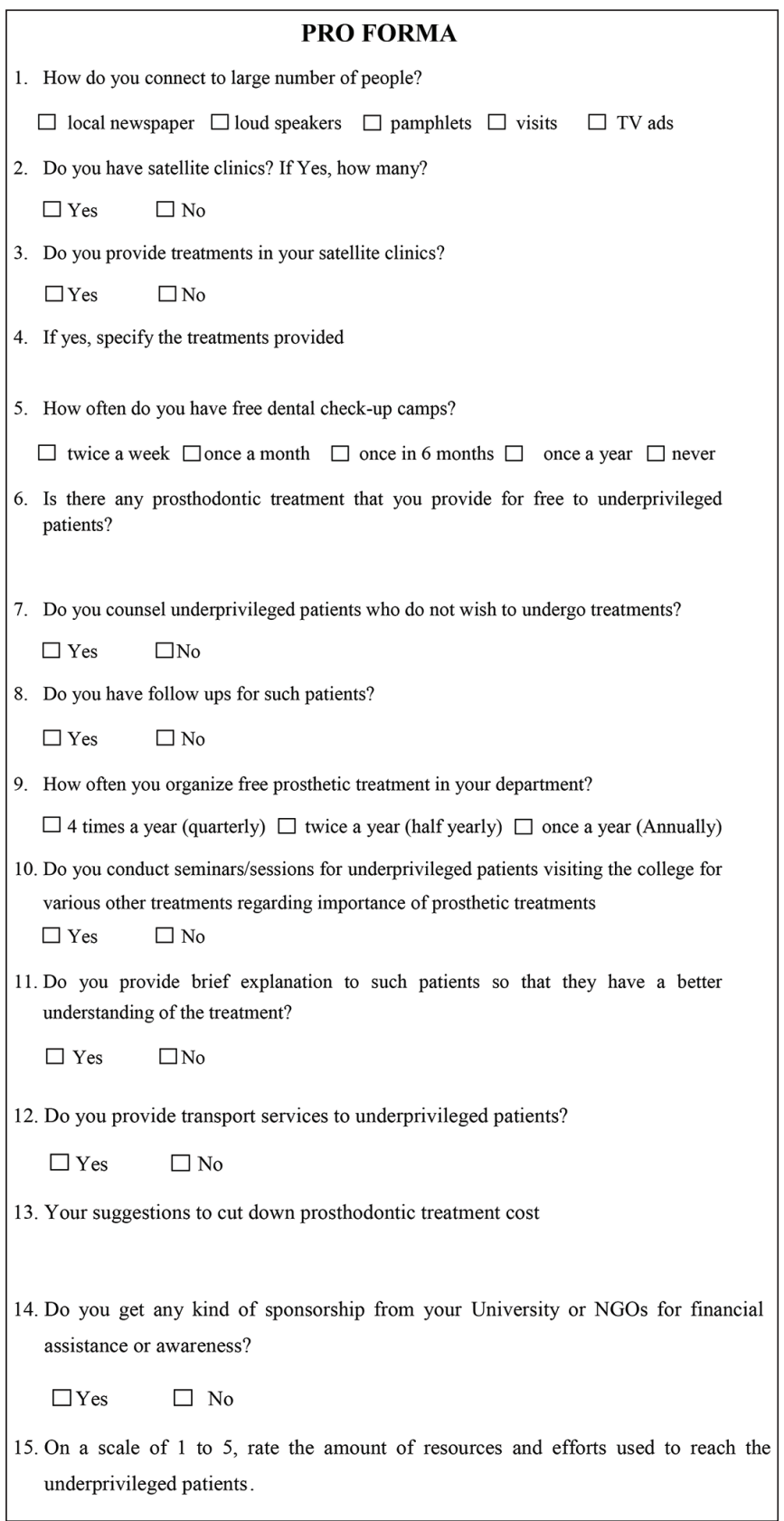

Fig. 1: Survey pro forma
After a 2-month interval, 86 answered questionnaires of the 289 mailed questionnaires were received. At this point of time, in order to increase the number of responses, a reminder letter was sent to the nonrespondent colleges stressing the importance of their participation and the urgency of returning the answered questionnaire. Following the reminder, 81 answered questionnaires were received thus bringing the total of answered questionnaires to 167. After data collection, it was compiled using Microsoft Excel and subjected to statistical analysis.

\section{Statistical Analysis}

The received questionnaires were analyzed according to the subject to which the questions referred. The data collected from these 167 answered questionnaires were analyzed to obtain the results. The statistical analysis was carried out using descriptive statistics, and the results were represented in percentage.

\section{RESULTS}

Of the 289 survey questionnaires mailed, 167 questionnaires were completed and returned. Thus, out of the 289 listed colleges, 167 , i.e., $58 \%$, participated in the survey (Graph 1).

\section{Method of Spreading Awareness of Dental Treatment}

For the question on methods of connecting to large number of people, $43 \%$ of colleges preferred local newspapers, while $36 \%$ preferred pamphlets as their means of spreading awareness and the remaining $10 \%$ used both of the above. Six percent colleges in rural areas preferred loud speakers and visits along with pamphlets (Graph 2).

All the colleges who responded had satellite clinic facility $(100 \%)$, while $92 \%$ provided treatment at their

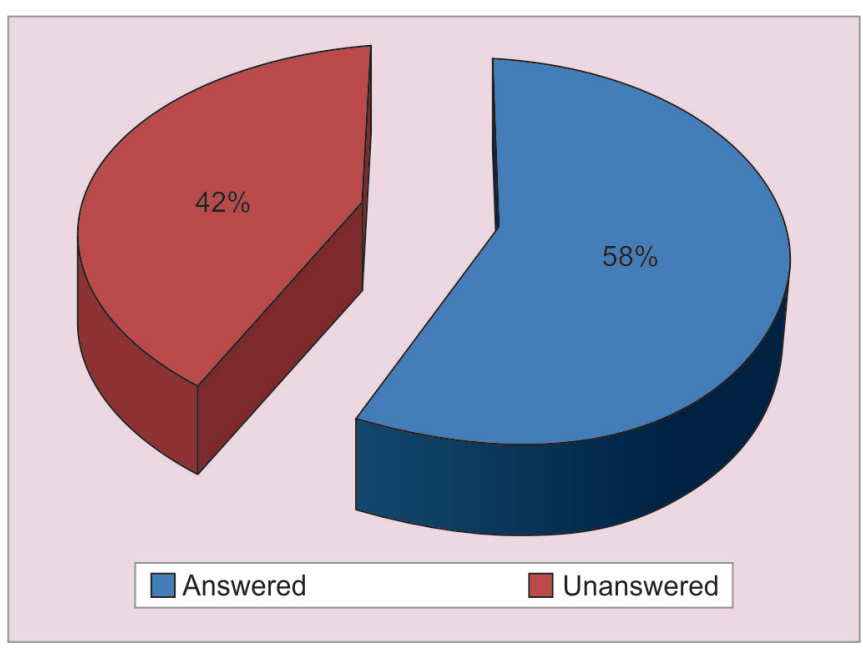

Graph 1: Participation statistics 


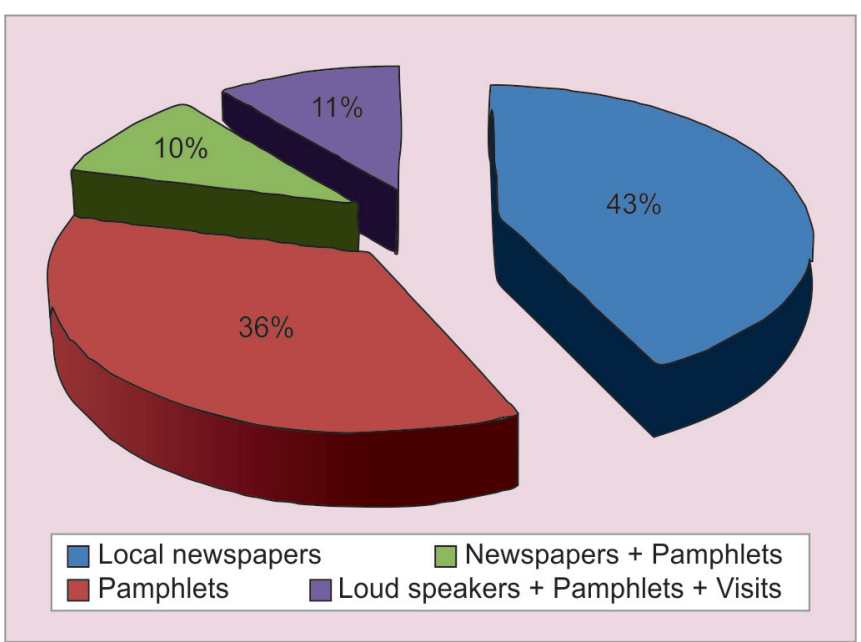

Graph 2: Method of spreading awareness

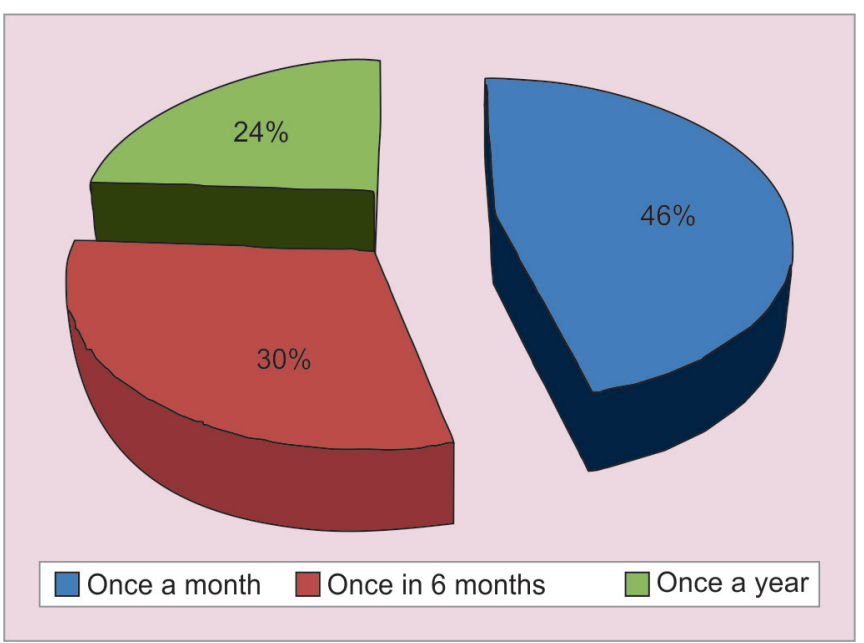

Graph 4: Free dental check-up camps

satellite clinics (Graph 3). The treatments varied from basic treatments like routine dental checkup, oral prophylaxis, and extractions to more complex treatments like root canal therapy and dentures. However, majority of the treatments were limited to oral prophylaxis and extractions.

As many as $46 \%$ of colleges held free dental check-up camps once a month, while $30 \%$ of colleges conducted it once in 6 months and remaining $24 \%$ conducted it once a year (Graph 4$)$.

\section{Cost-effectiveness of Dental Treatment}

A majority, i.e., 70\%, of colleges provided some prosthodontics treatments like removable partial dentures (RPD) or complete dentures (CD) free of cost, while 5\% treated patients with fixed partial dentures (FPD) free of cost. Some colleges provided all treatments other than FPDs free for below-poverty-line card holders.

In response to another question on frequency of free denture camps, $60 \%$ of the colleges held it once a year, while $40 \%$ held it twice a year (Graph 5).

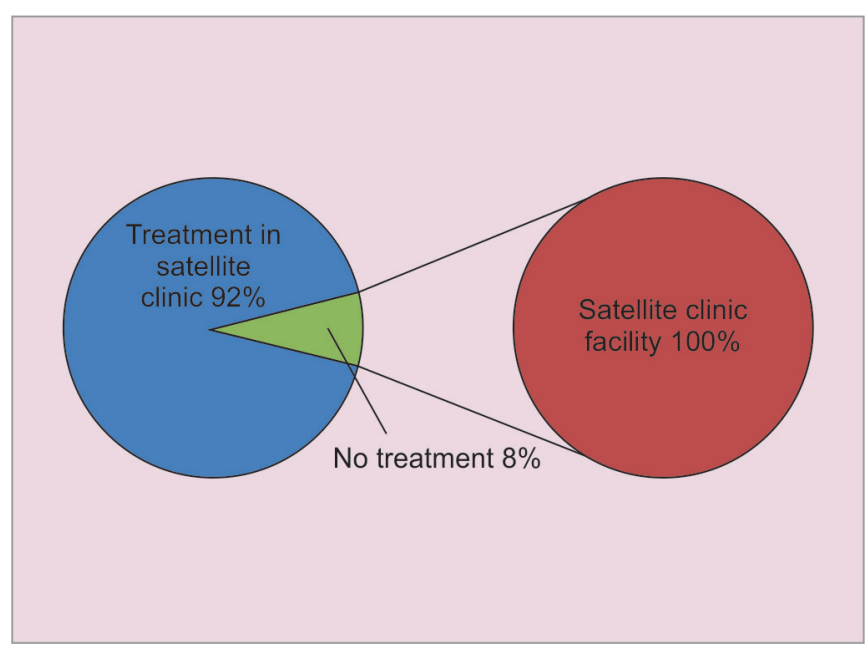

Graph 3: Satellite clinic facility

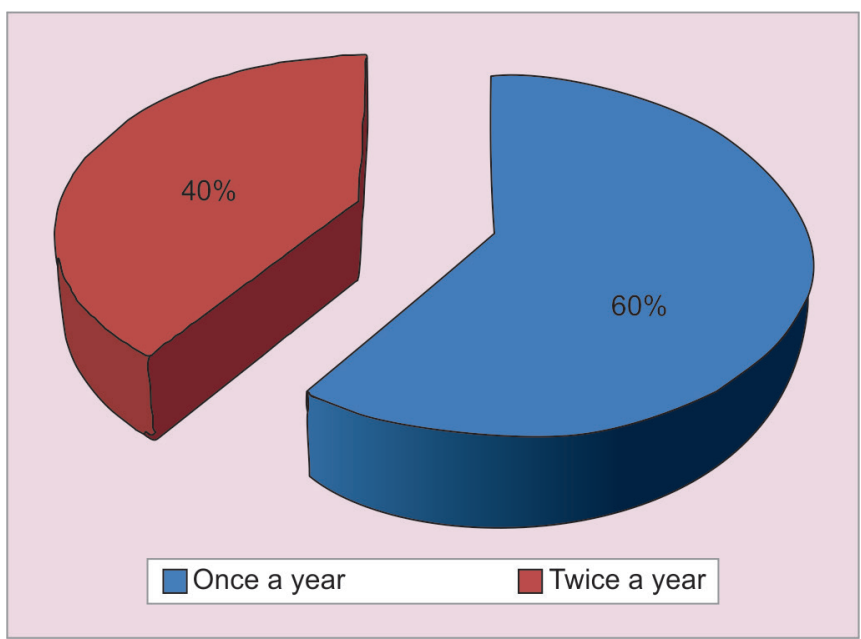

Graph 5: Frequency of free denture camps

In response to a question on suggestions to reduce prosthodontics treatment cost, the respondents were of the opinion that most of the treatment is already being provided free of cost (RPD, CD, etc.). For other treatments, they felt that only material charges should be taken, taxes on dental material should be removed, prosthetic labs should have government subsidy, and bulk purchase of material should be followed to reduce the treatment cost.

\section{Extension of Prosthodontic Treatment to Underprivileged Patients}

An overwhelming $92 \%$ of colleges have counseling for underprivileged patients who do not wish to undergo treatments in order to find out the reason and address the issue. As many as $85 \%$ of the colleges conducted seminars to counsel and educate the underprivileged patients regarding various prosthetic treatment options and their importance. They also provided brief explanations so that these patients would have a better understanding of the treatment. 


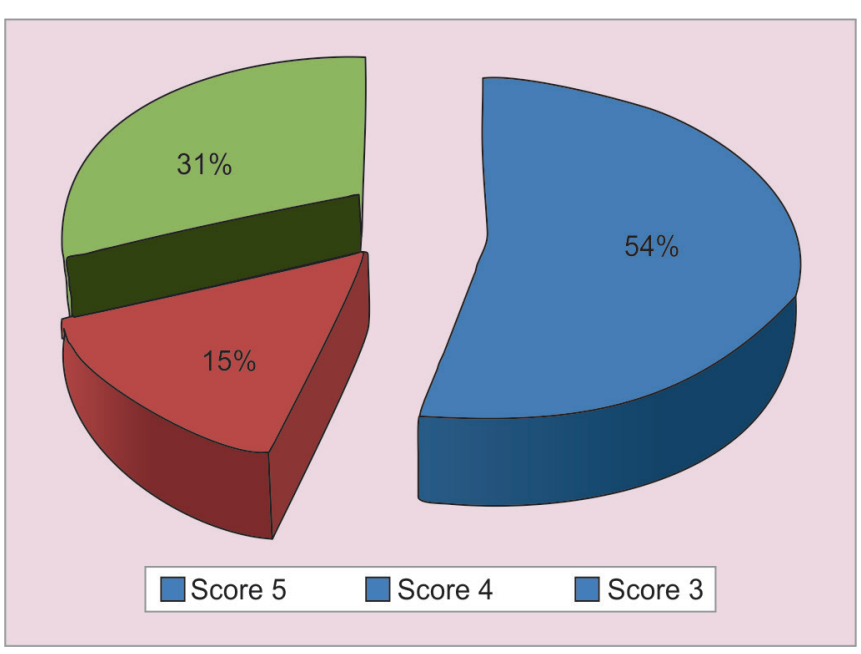

Graph 6: Resources and efforts

A majority, i.e., 73\%, of colleges provided free transport to the patients. Only 39\% colleges received sponsorship from their university or nongovernmental organizations as financial assistance to raise awareness. In response to a question to the respondents to rate their colleges on a scale from 1 to 5 on the amount of resources and efforts in reaching underprivileged patients, $54 \%$ of colleges rated themselves at a score of 5, 15\% rated themselves at score 4, while 31\% rated their score at 3 (Graph 6).

\section{DISCUSSION}

The urban dentist to population ratio is $1: 10,000$ as opposed to rural areas which is $1: 150,000{ }^{1}$ The number of qualified dentists in our country is found to be 118,000, still there is lack of availability of basic oral health education, resulting in poor oral health also affecting the quality and standard of life. ${ }^{1}$ Underprivileged patients are unaware of such treatments also due to their low socioeconomic status, mostly patients do not seek treatment immediately after tooth loss, even if replacement of missing teeth is strongly indicated which can render them completely edentulous before time.

Unfortunately, as most dental specialists in India are concentrated in urban areas, the semi-urban and rural areas are left underserved. The effect of geographical distance, socioeconomic inequality, and "rural-urban" developmental imbalance on oral health care in India is profound. Less than $20 \%$ of the existing primary health centers in India have the services of a dentist available. At the moment, India has 1 dentist for 10,000 persons in urban areas and 1 per 250,000 persons in rural areas. ${ }^{7}$ Almost three-fourths of all the dentists are clustered in the urban areas, which is home to only one-fourth of the country's population. ${ }^{7}$ It is often difficult for the urban poor and the rural population to get access to dental care. Dental colleges can fill this vacuum. Oral disease prevalence can be reduced by early identification, investigation, and providing the desired treatment which is possible by introducing dental outreach programs by dental colleges. A prosthodontic awareness and motivational program was undertaken by Sarang et $\mathrm{al}^{8}$ to help the aged and to change their attitude toward dental care and treatment. The community-based dental outreach programs play a very crucial role in introducing awareness through health education and dental treatment services to the community members. These programs are found to be very effective for diminishing health unevenness. The attendance and utilization of dental services in the outreach programs seem to be influenced by sociodemographic characteristics of the population.

Patients' income levels may preclude them from seeking routine dental care. Tuominen et $\mathrm{al}^{9}$ found financial constraints to be a main cause. Tennstedt et al ${ }^{10}$ reported disinterest as the most common reason for nonutilization of prosthodontic treatment in New England. The other reasons cited were unavailability/inaccessibility of services and systemic disease. ${ }^{10}$

There remains a need to educate patients as to the need for replacement/regular check-up of their prosthesis. Dental colleges should be at the forefront of bringing quality care to the underprivileged population.

A 3-year study conducted by Pawar et $\mathrm{al}^{11}$ showed dental outreach program to be very effective in improving oral status of schoolchildren during a 3-year follow-up period in Lucknow city. Studies by Berge reported media to be the main source of information. ${ }^{12}$

Various studies have demonstrated that early prevention can substantially reduce future dental care costs and one such dental outreach program (ABCD) in Washington has proved to be cost-effective method of improving oral health status of young children. ${ }^{13}$ Financial constraints are important determinants for seeking treatment and selecting a specific prosthodontic treatment option. ${ }^{14}$

Due to the limitations imposed by the type of evaluation (e-mail survey), the number of colleges that answered the questionnaire (58\%) can be considered satisfactory, and is comparable to a similar study done by Souza et $\mathrm{al}^{15}$ in 2002 , in which a rate of $60 \%$ of answers (33 schools) was accomplished.

Potential sources of bias in the present study include selection bias as the dental colleges were chosen from the colleges listed in the DCI website. The survey excluded colleges not listed on the website hence there could be a sampling bias, as a convenient type of sample was chosen. There could also be a design bias, as the survey questionnaire was e-mailed to the various dental colleges, and e-mail is a poor data collection method. Since only $58 \%$ of the colleges responded, making 
the nonresponse rate more than $15 \%$, it could also be a potential source of bias. Lastly, there could also be Hawthrone effect bias.

A single study assessed awareness, cost-effectiveness, and extension of prosthodontic treatment which indirectly gives information about utilization of oral health services provided. This is an important determinant to achieve "Health for all" goal. Also, even though e-mail is a poor data collection method, the survey had 167 respondents which was a satisfactory response. However, since it was a cross-sectional survey, it assessed the variables at one point of time and also the sample was a convenient type of sample which could result in bias. Also since the nonresponse rate was more than $15 \%$, it could be one of the weaknesses of the study.

\section{CONCLUSION}

The utilization of dental services can be improved by identifying the barriers and by providing appropriate education and intervention. The awareness of the participating colleges was quite high regarding the need for prosthodontics treatment, but a number of measures are required to make sure patients with low socioeconomic background get adequate access to dental care. Mobile dental clinics, separate geriatric dental outpatient departments, dental camps, free or subsidized dental treatment, and prosthodontic outreach programs are possible solutions to change attitudes, spread awareness, and extend treatment.

\section{REFERENCES}

1. Dagli R, Singh A. Dental Outreach Program-how effective it is in reaching out to the community. J Int Oral Health 2015 May;7(5):i-ii.

2. Shigli K, Hebbal M, Angadi GS. Attitudes towards replacement of teeth among patients at the institute of dental sciences, Belgaum, India. J Dent Educ 2007 Nov;71(11):1467-1475.
3. Tandon S. Challenges to the oral health workforce in India. J Dent Educ 2004 Jul;68(7 Suppl):28-33.

4. Pizarro V, Ferrer M, Domingo-Salvany A, Benach J, Borrell C, Pont A, Schiaffino A, Almansa J, Tresserras R, Alonso J. The utilization of dental care services according to health insurance coverage in Catalonia (Spain). Community Dent Oral Epidemiol 2009 Feb;37(1):78-84.

5. Angell BJ, Muhunthan J, Irving M, Eades S, Jan S. Global systematic review of the cost-effectiveness of indigenous health interventions. PLoS One 2014 Nov;9(11):e111249.

6. Azad A, Salma M, Ayesha A. Awareness about prosthodontic treatment for missing natural teeth among patients seen at AFID-Pakistan. Oral Dent J 2016;36:152-155.

7. Parlani S, Tripathi A, Singh SV. Increasing the prosthodontics awareness of an aging Indian rural population. Indian J Dent Res 2011 May-Jun;22(3):367-370.

8. Sarang P, Deshpande D, Nagda SJ. An evaluation of the oral health status of geriatric patients living in homes for aged-a survey. Indian Prosthod J 1999;10:17-20.

9. Tuominen R, Vehkalahti M, Ranta K, Rajala M, Paunio I. Development of edentulousness in Finland during the 1970's. Community Dent Oral Epidemiol 1983 Aug;11(4):259-263.

10. Tennstedt SL, Brambilla DL, Jette AM, McGuire SM. Understanding dental service use by older adults: sociobehavioral factors vs need. J Public Health Dent 1994 Fall;54(4):211-219.

11. Pawar H, Saha S, Jagannath G, Kumari M, Narang R, Singh E. Effectiveness of outreach program: a three year follow-up study among 12 years school students in Lucknow. J Clin Diagn Res 2015 Jan;9(1):35-38.

12. Satpathy A, Porwal A, Bhattacharya A, Sahu PK. Patient awareness, and perceived cost of dental implants as a treatment modality for replacement of missing teeth: a survey in Bhubaneswar and Cuttack. Int J Pub Health Dent 2011;2:1-7.

13. Kobayashi M, Chi D, Coldwell SE, Domoto P, Milgrom P. The effectiveness and estimated costs of the access to baby and child dentistry program in Washington State. J Am Dent Assoc 2005 Sep;136(9):1257-1263.

14. Teofilo LT, Leles CR. Patients' self-perceived impacts and prosthodontic needs at the time and after tooth loss. Braz Dent J 2007;18(2):91-96.

15. Souza RF, Leles CR, Marco A. A survey of complete denture teaching in Brazilian Dental Schools. J Brazilian Dent Sci 2002;5(1):5-11. 